\title{
Выделение из гальваношламов гидроксида никеля и применение для изготовления катода $\mathrm{Ni}-\mathrm{Cd}$ аккумулятора
}

\author{
Л. Н. Ольшанская ${ }^{1, *}$, Е. Н. Лазарева ${ }^{1}$, Е. В. Яковлева ${ }^{1}$ \\ ${ }^{1}$ Саратовский государственный технический университет имени Гагарина Ю. А. \\ (СГТУ имени Гагарина Ю. А.), Саратов, Россия
}

\begin{abstract}
Аннотация
Наблюдаемый в последнее время рост объемов производства промышленных никелькадмиевых аккумуляторов (HKA) при одновременном сокращении природных ресурсов стимулирует исследования, целью которых является вовлечение отходов в ранг вторичных материальных ресурсов для производства товаров народного потребления, в том числе - изготовление электродов для аккумуляторов различных классов.

В статье представлены результаты изучения процесса извлечения гидроксида никеля (II) из никель содержащего гальваношлама II класса опасности для изготовления положительных оксидно-никелевых электродов (ОНЭ-катодов) никель-кадмиевых (железных) аккумуляторов (HK/ЖK/A). Это позволяет считать, что использование таких отходов не только снижает их вредное воздействие на окружающую природную среду, но и одновременно позволяет превратить гальваноотходы во вторичные сырьевые ресурсы для получения товаров, имеющих народнохозяйственное значение. Проведенные лабораторные и производственные испытания $\mathrm{Ni}(\mathrm{OH})_{2}$ катодов, изготовленных на основе гидроксида никеля, выделенного из гальваношлама, показали высокую стабильность, длительность работы, хорошие электрохимические характеристики при работе в условиях производственного режима. Параметры по ёмкости 0,930-1,014 А·ч и коэффициенту использования 83-86 \% в течение более 110 зарядно-разрядных циклов удовлетворяют требованиям, предъявляемым к электродам такого типа.
\end{abstract}

\section{Ключевые слова}

гальваношлам, гидроксид никеля (II), оксидно-никелевый электрод (катод), никелькадмиевые (железные) аккумуляторы

Введение. Перезаряжаемые химические источники тока широко применяются в различных отраслях народного хозяйства (речные и морские суда, городской наземный и подземный электротранспорт и др.) При этом дорогостоящие новые электрохимические системы в этих сферах пока остаются невостребованными. Потребителей при выборе известных систем интересует их стоимость, надежность и безопасность работы в течение длительного времени. K числу наиболее применяемых вторичных источников тока, несмотря на проблемы, связанные с экологичностью их изготовления, относятся щелочные никель-кадмиевые (железные) аккумуляторы (HK(Ж)A) [1,2]. Эти аккумуляторы благодаря своим 
эксплуатационным свойствам: хорошая работоспособность при отрицательных температурах, устойчивость к перезарядам, высокая удельная мощность, низкая стоимость, большой ресурс работы и др., в настоящее время пользуются большим спросом.

Наблюдаемый в последнее время рост объемов производства промышленных HКА при одновременном сокращении природных ресурсов стимулирует исследования, целью которых является вовлечение отходов в ранг вторичного сырья для производства товаров народного потребления, в том числе - для изготовления электродов для аккумуляторов различных классов.

В связи с этим применение отходов гальваношламов (ГШ) для изготовления активной массы электродов щелочных аккумуляторов, отличающихся высокими эксплуатационными характеристиками, весьма целесообразно. Основным материалом активной массы оксидно-никелевого электрода (ОНЭ) щелочных $\mathrm{Ni}-\mathrm{Cd}(\mathrm{Fe})$ аккумуляторов является гидроксид никеля (II) [1 - 3]. Минералы такого состава в природе не встречаются, $\mathrm{Ni}(\mathrm{OH})_{2}$ получают осаждением из растворов различных солей никеля через промежуточную стадию образования продуктов переменного состава. Этот состав зависит от многих факторов: природы и концентрации солей никеля, применяемых осадителей, условий процесса осаждения и др. [3-6].

Авторами [7] предложен предположительный химизм протекающих процессов перехода сульфидов, гидроксидов и карбонатов металлов в водорастворимые хлориды при использовании хлорида натрия:

для сульфидов

$$
\begin{gathered}
\mathrm{NiS}+2 \mathrm{NaCl}+2 \mathrm{O}_{2} \rightarrow \\
\mathrm{NiCl}_{2}+\mathrm{Na}_{2} \mathrm{SO}_{4}
\end{gathered}
$$

для карбонатов

$$
\begin{gathered}
\mathrm{NiCO}_{3}+2 \mathrm{NaCl}+0,5 \mathrm{O}_{2} \rightarrow \\
\mathrm{NiO}+\mathrm{Na}_{2} \mathrm{O}+\mathrm{CO}_{2}+\mathrm{Cl}_{2} \\
2 \mathrm{NiO}+2 \mathrm{Cl}_{2} \rightarrow 2 \mathrm{NiCl}_{2}+\mathrm{O}_{2}
\end{gathered}
$$

Далее при обработке полученных солей никеля щелочью в выбранной области pH можно получить гидроксид никеля (II):

$$
\mathrm{NiCl}_{2}+2 \mathrm{NaOH} \rightarrow \mathrm{Ni}(\mathrm{OH})_{2}+2 \mathrm{NaCl}
$$

Целью настоящей работы явилось изучение извлечения гидроксида никеля (II) из никель содержащего гальваношлама и использования его в качестве основного компонента активной массы катода никель-кадмиевого (железного) аккумулятора. В работе решались следующие задачи:

1. Исследовать процессы извлечения гидроксида никеля (II) из ГШ, содержащих никель, определить рациональные условия их извлечения и соответствие ГОСТ и продуктам, используемым в промышленности.

2. Разработать способ получения оксидно-никелевого электрода (катода) на основе извлеченного $\mathrm{Ni}(\mathrm{OH})_{2}$.

3. Провести исследование электрохимических характеристик полученных ОНЭ-катодов и установить их соответствие требованиям ГОСТ.

Результаты. Объектом исследования в работе служил гальваношлам, образовавшийся после ванн никелирования на предприятии ОАО «Роберт-Бош-Саратов» г. Энгельса Саратовской области.

Для определения фазового состава проводили рентгенофазовый анализ ГШ на дифрактометре ДРОН-3 с рентгеновской трубкой БСВ-27 (Cu kx- излучение и никелевый фильтр) $[4,5]$.

На основании анализа спектров установлены следующие значения концентраций элементов в исходном ГШ в масс. \%: в наибольшем процентном соотношении 
содержатся $\mathrm{Ni}-64,59, \mathrm{Fe}-29,65$, в незначительных количествах присутствуют $\mathrm{Si}-1,11, \mathrm{Zn}-0,53, \mathrm{Cu}-0,47$, $\mathrm{Mn}-0,11, \mathrm{Cr}-0,06$ и др.

Для извлечения гидроксида никеля исходный ГШ смешивали с дистиллированной водой до консистенции сметаны. На следующем этапе в раствор добавляли концентрированную серную кислоту $\mathrm{H}_{2} \mathrm{SO}_{4}$, доводя кислотность до $\mathrm{pH}=2$, при которой достигалось наиболее высокое растворение и переход компонентов гальваношлама в сульфаты металлов.

После этого полученный раствор отделяли от глинисто-песочного осадка путем фильтрования. Отобранный раствор, содержащий растворенные сульфаты металлов, использовали для выделения гидроксида никеля. При этом проводили щелочную обработку полученных сульфатных растворов $40 \%$-ной щелочью $\mathrm{NaOH}$ для избирательного осаждения нерастворимых гидроксидов металлов при определенных для каждого из них значениях $\mathrm{pH}$ [8] (таблица 1).

Таблица 1 - Последовательный ряд осаждения гидроксидов металлов из кислого раствора [8]

\begin{tabular}{|c|c|}
\hline Ион & $\mathrm{pH}^{*}$ \\
\hline $\mathrm{Fe}(\mathrm{III})$ & $1,5^{*}-4,1^{* *}$ \\
\hline $\mathrm{Cr}(\mathrm{III})$ & $4,0-6,8$ \\
\hline $\mathrm{Cu}(\mathrm{II})$ & $5,3-6,2$ \\
\hline $\mathrm{Zn}$ & $5,4-8,0$ \\
\hline $\mathrm{Fe}(\mathrm{II})$ & $6,5-9,7$ \\
\hline $\mathrm{Ni}(\mathrm{II})$ & $6,7-9,5$ \\
\hline $\mathrm{Mn}(\mathrm{II})$ & $7,8-10,4$ \\
\hline $\mathrm{Mg}$ & $9,4-12,4$ \\
\hline
\end{tabular}

первая иифра ${ }^{*}$ - начало осаждения; вторал*** - полное осаждение гидроксида

Для извлечения $\mathrm{Ni}(\mathrm{OH})_{2}$ из ГШ вначале в диапазоне $\mathrm{pH}=1,5 \ldots 7,0$ отделяли и отфильтровывали гидроксиды железа, далее - гидроксиды хрома, цинка и меди (их было очень мало), а при достижении $\mathrm{pH}>7,0$ (до $\sim \mathrm{pH}=9,0)$ образовывались хлопья салатного цвета, соответствующие гидроксиду $\mathrm{Ni}(\mathrm{OH})_{2}$, который использовали для изготовления активной массы положительных электродов (катодов) никель-кадмиевых и никель-железных аккумуляторов $[9,10]$.

$$
\begin{aligned}
& \mathrm{NiSO}_{4}+2 \mathrm{NaOH} \rightarrow \\
& \mathrm{Ni}(\mathrm{OH})_{2}+\mathrm{Na}_{2} \mathrm{SO}_{4}
\end{aligned}
$$

Исследовано влияние величины $\mathrm{pH}$ при выщелачивании на стадии растворения и выделения сульфата никеля на количество извлеченного гидроксида никеля при его последующем осаждении щелочью. Выявлено, что наибольшее количество сульфатов металлов на стадии выщелачивания образуется при $\mathrm{pH}=2$. В этих условиях было также установлено и наибольшее количество извлеченного $\mathrm{Ni}(\mathrm{OH})_{2}$ при $\mathrm{pH}=7,7 \pm 0,5$ (таблица 2).

Таблица 2 - Данные по извлечению $\mathrm{Ni}(\mathrm{OH})_{2}$ из ГШ на стадии осаждения в зависимости от величины $\mathrm{pH}$ раствора

\begin{tabular}{|c|c|c|}
\hline $\begin{array}{c}\text { Значение } \\
\text { рН рас- } \\
\text { твора }\end{array}$ & $\begin{array}{c}\text { Доля из- } \\
\text { влечения } \\
\mathrm{Ni}(\mathrm{OH})_{2}\end{array}$ & $\begin{array}{c}\text { Количество } \\
\mathrm{Ni}(\mathrm{OH})_{2}, \\
\text { масс. } \%\end{array}$ \\
\hline 6 & 0,5630 & 56,30 \\
\hline 5 & 0,5691 & 56,91 \\
\hline 4 & 0,5711 & 57,11 \\
\hline 3 & 0,5764 & 57,64 \\
\hline 2 & 0,5812 & 58,42 \\
\hline 1 & 0,5836 & 58,46 \\
\hline
\end{tabular}

Установленная плотность выделенного $\mathrm{Ni}(\mathrm{OH})_{2}$ составила $3,96-4,12$ г $/ \mathrm{cm}^{3}$. По ТУ 48-3-63-90 [11] этот параметр соответствует гидроксиду никеля 4,09-4,10 г/ $\mathrm{cm}^{3}$, то есть получено подтверждение его состава. Проведенный ситовой анализ гидроксида никеля показал, что 94,2 \% частиц имеют размер менее 15 мкм, что является приемлемым при изготовлении электродов 
аккумуляторных батарей без предварительного измельчения. Состав выделенного кислотно-щелочным методом гидроксида никеля из ГШ контролировали с помощью дериватографического метода (дериватограф Q-1500Д в области температур от 20 до $1000^{\circ} \mathrm{C}$ со скоростью нагрева $10{ }^{\circ} \mathrm{C} / \mathrm{мин,} \mathrm{ра-}$ бочая среда - сухой воздух), который позволил установить в составе $\mathrm{Ni}(\mathrm{OH})_{2}$ остаточные количества компонентов гальваношлама (таблица 3 ).

Сравнение полученных результатов анализа степени чистоты полученного нами гидроксида никеля с характеристиками $\mathrm{Ni}(\mathrm{OH})_{2}$, используемого для изготовления электродов на предприятии ОАО «Завод АИТ», показало, что полученный $\mathrm{Ni}(\mathrm{OH})_{2}$ может применяться для изготовления катодов никель-кадмиевых и никель-железных аккумуляторов.

Состав гидроксида никеля контролировали по стандартной методике в лаборатории предприятия ОАО «Завод АИТ» (г. Саратов) титриметрическим (с трилоном Б) (для оценки содержания $\mathrm{Ni}(\mathrm{OH})_{2}$ ) и фотометрическим (для оценки содержания $\mathrm{SO}_{4}{ }^{2-}$ ) методами (таблица 4) и сравнивали с требованиями [11].

Было установлено, что в составе выделенного нами гидроксида никеля содержатся сульфат-ионы, в концентрациях, превышающих нормативы [11], что может негативно сказаться на разрядных характеристиках электродов.

Таблица 3 - Данные дериватографического анализа $\mathrm{Ni}(\mathrm{OH})_{2}$ выделенного нами кислотно-щелочным растворением - осаждением (числитель) и применяемого на предприятии ОАО «Завод автономных источников тока» («Завод АИТ») г. Саратов (знаменатель)

\begin{tabular}{|l|l|l|}
\hline Наименование компонента & Количество, масс. \% & $\begin{array}{l}\text { Количество, масс. \% по } \\
\text { ТУ 48-3-63-90 [11] }\end{array}$ \\
\hline $\mathrm{Ni}$ & $58,42 / 59,4-60,9$ & $\mathrm{He}<58,5$ \\
\hline влага & $3,5-3,6 / 0,6-3,5$ & $0,5-5,4$ \\
\hline $\mathrm{Cu} / \mathrm{Ni}$ & $0,008 / 0,006$ & $\mathrm{He}>0,015$ \\
\hline $\mathrm{Mg} / \mathrm{Ni}$ & $0,117-0,120 / 0,08-0,118$ & $\mathrm{He}>0,15$ \\
\hline $\mathrm{Fe} / \mathrm{Ni}$ & $0,108 / 0,02-0,03$ & Не $>0,12$ \\
\hline Механические примеси & Не обнаружены & Не обнаружены \\
\hline
\end{tabular}

Таблица 4 - Содержание компонентов в составе выделенного из ГШ гидроксида никеля при различных значениях $\mathrm{pH}$.

\begin{tabular}{|c|c|c|c|c|c|c|}
\hline \multirow[t]{3}{*}{$\begin{array}{l}\text { Наименование } \\
\text { понента }\end{array}$} & \multicolumn{6}{|c|}{$\begin{array}{l}\text { Содержание компонентов в составе выделенного при различных } \\
\text { значениях рН вещества, масс. \% }\end{array}$} \\
\hline & \multicolumn{5}{|c|}{ pH раствора } & \multirow{2}{*}{$\begin{array}{c}\text { Требования } \\
\text { ТУ 48-3-63-90 [11] }\end{array}$} \\
\hline & $\mathrm{pH}=6$ & $\mathrm{pH}=5$ & $\mathrm{pH}=4$ & $\mathrm{pH}=3$ & $\mathrm{pH}=2$ & \\
\hline $\mathrm{Ni}^{2+}$ & 56,30 & 56,91 & 57,11 & 57,64 & 58,42 & не $<58,5$ \\
\hline $\mathrm{SO}_{4}{ }^{2-}$ & 1,74 & 1,95 & 2,28 & 2,63 & 4,58 & не $>0,7$ \\
\hline $\mathrm{Cl}^{-}$ & 0,02 & 0,02 & 0,02 & 0,03 & 0,03 & не $>0,2$ \\
\hline $\mathrm{Ca}^{2+}$ & 0,005 & 0,005 & 0,005 & 0,06 & 0,07 & не $>0,2$ \\
\hline
\end{tabular}


Перед изготовлением электродов проводили дополнительную тщательную промывку полученной массы $\mathrm{Ni}(\mathrm{OH})_{2}$ дистиллированной водой методом декантации для снижения содержания сульфат-ионов. Недостатком способа является потеря компонента гидроксида никеля при промывке. Результаты анализа состава образцов после декантации представлены в таблице 5 .

Как видно из представленных результатов, образец отличается от требований [11] по процентному содержанию ионов $\mathrm{Ni}^{2+}, \mathrm{C1}^{-}$и $\mathrm{SO}_{4}{ }^{2-}$.

\section{Исследование} электрохимических характеристик ОНЭ, изготовленных из $\mathrm{Ni}(\mathrm{OH})_{2}$

Учитывая допустимые отклонения в составах полученного и промышленного
$\mathrm{Ni}(\mathrm{OH})_{2}$ мы провели испытания электрохимической активности нашего гидроксида никеля в составе положительной активной массы электродов типа $\mathrm{KH}(\mathrm{KL})$, результаты анализа которой представлены в таблице 6 .

Как видно из таблицы 6 , в составе положительной активной массы наблюдается повышенное содержание железа.

По стандартной методике «Завода АИТ» были изготовлены 3 ламели с навеской 7,5 г и проведены их макетные испытания в лаборатории ОАО «Завод АИТ» г. Саратова. Испытания положительной активной массы, изготовленной на основе извлеченного гидроксида никеля проводили в электролите состава — раствор КОН плотностью $1,19 \cdot 10^{3}-1,21 \cdot 10^{3} \mathrm{Kг} / \mathrm{m}^{3} \mathrm{c}$ добавкой $10 \mathrm{kг} / \mathrm{m}^{3} \mathrm{LiOH} \cdot \mathrm{H}_{2} \mathrm{O}$.

Таблица $\mathbf{5}$ - Данные по анализу массы $\mathrm{Ni}(\mathrm{OH})_{2}$ после отмывки от сульфат-ионов

\begin{tabular}{|c|c|c|c|}
\hline \multirow{2}{*}{$\begin{array}{l}\text { Наименованиентов ком- } \\
\text { поненультаты анализа, масс.\% }\end{array}$} & $\begin{array}{l}\text { Требование } \\
\text { ТУ 48-3-63-90 [11] }\end{array}$ \\
\cline { 2 - 4 } & исходный & $\begin{array}{c}\text { После } \\
1 \text { отмывки } / 2 \text { отмывки }\end{array}$ & $\geq 58,5$ \\
\hline $\mathrm{Ni}^{2+}$ & 58,42 & $55,3 / 54,2$ & $\leq 0,2$ \\
\hline $\mathrm{C1}^{-}$ & 1,0 & $0,7 / 0,6$ & $0,5-5,4$ \\
\hline влага & 15 & 4 & $\leq 0,2$ \\
\hline $\mathrm{Cu}^{2+}$ & 0,009 & & $\leq 0,4$ \\
\hline $\mathrm{Ca}^{2+}$ & 0,07 & $2,0 / 2,3$ & $\leq 0,2$ \\
\hline $\mathrm{Fe}_{\text {общ }}$ & 1,5 & $1,24 / 1,11$ & $\leq 0,9$ \\
\hline $\mathbf{S O}_{4}{ }^{2-}$ & 4,58 & - & - \\
\hline Механич. примеси & - & & \\
\hline
\end{tabular}

Таблица 6 - Состав активной массы катода никель-кадмиевого аккумулятора

\begin{tabular}{|l|c|l|l|l|l|l|c|}
\hline Компонент & $\mathrm{Ni}(\mathrm{OH})_{2}$ & $\mathrm{C}$ & $\mathrm{Co}$ & $\mathrm{Fe}$ & $\mathrm{Mg}$ & $\mathrm{Ba}$ & влага \\
\hline Содержание, \% & 54,2 & 18,4 & 2,4 & 2,3 & 0,006 & 2,6 & 10,1 \\
\hline Требование [11], \% & $\geq 41,5$ & $\geq 17,0$ & $\geq 1,5$ & $\leq 0,4$ & $\leq 0,2$ & $\geq 1,7$ & $10-12,5$ \\
\hline
\end{tabular}




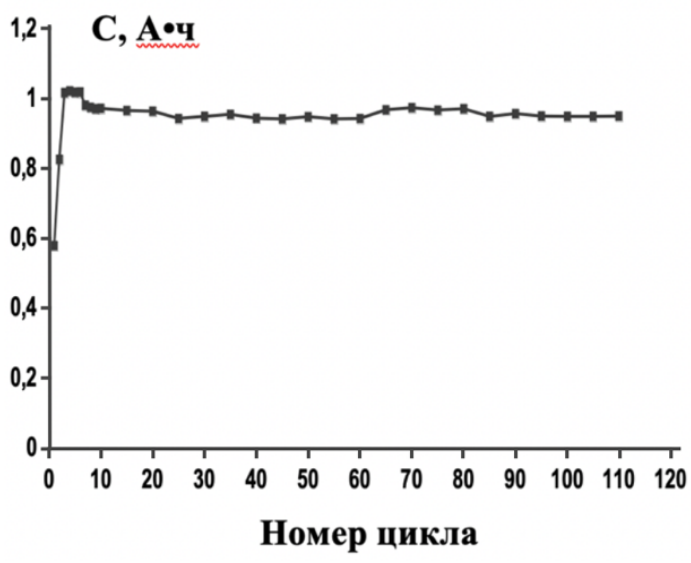

a)

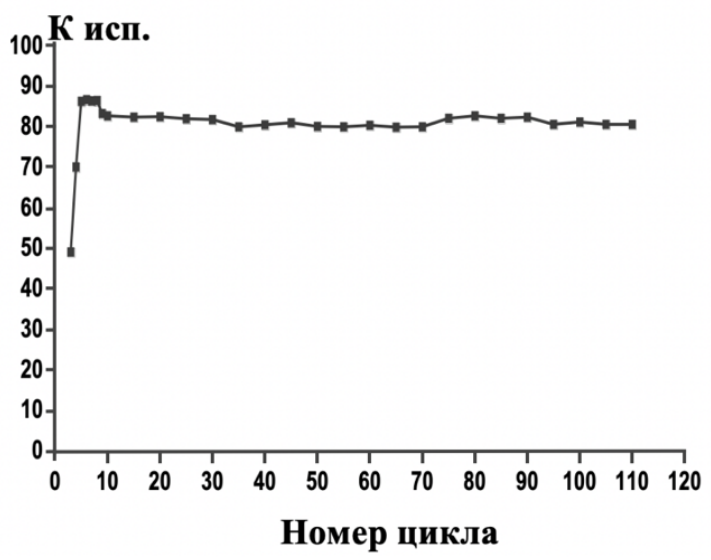

б)

Рисунок 1 - Зависимость величин емкости (а), отдаваемой электродами, изготовленными из $\mathrm{Ni}(\mathrm{OH})_{2}$, полученного из ГШ и коэффициента использования никеля (б) от длительности циклирования аккумуляторов.

Формирование электродов и наработку в течение 110 циклов проводили производственным режимом: заряд током 200 мА в течение 12 ч, разряд током 140 мА до потенциала 1,58 В относительно цинкового электрода сравнения. Результаты проведенных испытаний при формировании электродов представлены на рисунке 1. Установлено, что ёмкость положительной активной массы постепенно увеличивалась до 6 цикла включительно (с 0,574 A·ч до 1,014 А·ч и с коэффициентом использования 48,7\% и 86,1 \% для 1 и 6 циклов, соответственно). При циклировании НКА в течение 110 зарядно-разрядных циклов ёмкость стабилизировалась и составила порядка 0,944-0,976 А·ч с коэффициентом использования 80,1-82,9\%, что удовлетворяет требованиям, предъявляемым к ним.

\section{Заключение}

Изучен процесс извлечения из никель содержащего ГШ гидроксида никеля (II), который использован в качестве основного компонента оксидно-никелевого катода для никель-кадмиевых (железных) аккумуляторов. При этом решаются две важные проблемы: 1 - утилизация токсичного ГШ, что снижает вредное воздействие таких отходов на окружающую природную среду и позволяет превратить гальваноотходы во вторичные сырьевые ресурсы; и 2 - получение товарного продукта ОНЭ (катода) для $\mathrm{Ni}-\mathrm{Cd}(\mathrm{Fe})$ аккумуляторов.

Лабораторные и производственные испытания $\mathrm{Ni}(\mathrm{OH})_{2}$ катодов, изготовленных на основе гидроксида никеля, выделенного из гальваношлама, показали высокую стабильность, длительность работы, хорошие электрохимические характеристики при работе в условиях производственного режима. Параметры НKА в течение более 110 зарядно-разрядных циклов по емкости составили 0,930-1,014 А·ч и коэффициенту использования 83-86 \%, что удовлетворяет требованиям, предъявляемым к ним.

\section{СПИСОК ЛИТЕРАТУРЫ}

[1]. Хрусталёв Д. А. Аккумуляторы. М., Изумруд, 2008, 220 с.

[2]. Волынский В. А. Новые технологии получения и переработки электродных материалов для никель-кадмиевых аккумуляторов: дисс. докт. технич. наук /Волынский Виталий Анатольевич. Саратов, СГТУ, 2007, 334 c. 
[3]. Song Q.S., Li Y.Y., Chan S.L. Physical and electrochemical characteristics of nanostructured nickel hydroxide powder. J. of Applied Electrochemistry, 2005, vol. 35, № 2, pp. 157-162.

[4]. Волынский В. В., Попова С. С. Улучшение электрохимических характеристик никель-кадмиевого аккумулятора с намазными электродами волокновой структуры. Журнал Прикладной химии. 1999. т. 72. №5. С. 785-789.

[5]. Волынский В. В. и др. Снижение материальных и энергетических затрат при производстве гидроксида никеля (II) в ОАО «Завод АИТ». Электрохимическая энергетика. 2006. т. 6. № 3. С. 150-156.

[6]. Патент № 2310951 РФ. Способ получения гидрата закиси никеля для оксидно-никелевого электрода щелочного аккумулятора. МПК Н01M 10/30, МПК Н01М 4/26 / Волынская В. В., Волынский В. В., Лопашев А. В., Семенов Н. Е., Тюгаев В. Н., Чипига И. В.: заявитель и патентообладатель Открытое Акционерное общество «Завод автономных источников тока. Заяв. 30.03.2006, опубл. 20 ноября 2007 г.
[7]. Верболь С. В, Запарий М. М., Козлов В. В. и др. Обезвреживание гальваношламов с выделением металлов. Экология и промышленность России. 2000, апрель. С. 28-29.

[8]. Лурье Ю. Ю. Справочник по аналитической химии. М., Химия, 1971, 454 с.

[9]. Лазарева Е. Н., Егоров В. В., Ольшанская Л. Н. и др. Переработка металлосодержащих гальваношламов в peaгенты многофункционального назначения. Эколого-правовые и экономические аспекты техногенной безопасности регионов: материалы V Междунар. научнопрактической конференции г. Харьков 19 - 21 октября 2011 г. Харьков, ХНАДУ, 2011, c. $324-327$.

[10]. Лазарева Е. Н., Ольшанская Л. Н., Егоров В. В. и др. Использование шламов гальванических производств при изготовлении товаров народного потребления. Журнал «Ползуновский вестник». 2011. № 4-2. С. 203-206.

[11]. ТУ 48-3-63-90. Никеля гидрат закиси. - Л., Стандартизация и метрология, 1990, 36 с. [Документ ТУ 48-3-63-90 предоставлен предприятием ООО «Производственная Компания Лантан» и передан 02.10.2019 г.]

Ольшанская Любовь Николаевна - д-р хим. наук, профессор, кафедра «Экология и техносферная безопасность» ФГБОУ ВО «Саратовский государственный технический университет имени Гагарина Ю. А.» (Российская Федерация, 410054, Саратов, ул. Политехническая 77).

Лазарева Елена Николаевна - канд. хим. наук, доцент, кафедра «Естественные и математические науки» ФГБОУ ВО «Саратовский государственный технический университет имени Гагарина Ю. А.» (Российская Федерация, 410054, Саратов, ул. Политехническая 77).

Яковлева Елена Владимировна - канд. хим. наук, доцент, кафедра «Экология и техносферная безопасность» ФГБОУ ВО «Саратовский государственный технический университет имени Гагарина Ю. А.» (Российская Федерация, 410054, Саратов, ул. Политехническая 77). 


\title{
Isolation of nickel hydroxide from galvano sludges and application for the manufacture of a Ni-Cd battery cathode
}

\author{
L. N. Olshanskaya ${ }^{1, *}$, E. N. Lazareva ${ }^{1}$, E. V. Yakovleva ${ }^{1}$ \\ ${ }^{1}$ Yuri Gagarin State Technical University of Saratov, Saratov Russia
}

\begin{abstract}
The recent increase in the production of industrial NSA with a simultaneous reduction in natural resources stimulates research, the purpose of which is to involve waste in the rank of secondary material resources to produce consumer goods, including the manufacture of electrodes for batteries of various classes.

The article presents the results of studying the process of extracting nickel (II) hydroxide from nickel-containing galvanic sludge of hazard class II for the manufacture of positive oxide-nickel electrodes (ONE-cathodes) of nickel-cadmium (iron) batteries (NK/ W/ A). This allows us to believe that the use of such wastes not only reduces their harmful effects on the environment, but at the same time makes it possible to turn galvanized waste into secondary raw materials for obtaining goods of national economic importance. Laboratory and production tests of $\mathrm{Ni}(\mathrm{OH})_{2}$ cathodes made on the basis of nickel hydroxide isolated from galvanic sludge have shown high stability, durability, good electrochemical characteristics when operating under production conditions. The parameters in terms of capacity 0,930-1,014 Ah and a utilization rate of $83-86 \%$ for more than 110 charge and discharge cycles meet the requirements for electrodes of this type.
\end{abstract}

\section{Keywords}

galvanic sludge, nickel (II) hydroxide, oxide-nickel electrode (cathode), nickel-cadmium (iron) batteries

\section{REFERENCES}

[1]. Khrustalev D. A. Batteries. - M: [4]. Volynsky, V. V., Popova S. S. ImprovIzumrud, 2008 . - $220 \mathrm{p}$.

[2]. Volynsky, V.A. New technologies for the production and processing of electrode materials for nickel-cadmium batteries: diss. doct. technical Nauk / Volynsky Vitaly Anatolyevich. - Saratov: SSTU, 2007. - 334 p. (In Russ.)

[3]. $\quad$ Song Q.S., Li Y.Y., Chan S.L. Physical and electrochemical characteristics of nanostructured nickel hydroxide powder // J. of Applied Electrochemistry, 2005, vol. 35, № 2, pp.157-162. ing the electrochemical characteristics of a nickel-cadmium battery with fiber-bonded electrodes. // Journal of Applied Chemistry, 1999, v. 72, no. 5, p. 785-789. (In Russ.)

[5]. Volynsky V.V. et al. Reducing material and energy costs in the production of nickel (II) hydroxide in JSC "Plant AIT" // Electrochemical energy, 2006, v.6, № 3, pp. 150-156. (In Russ.)

[6]. Patent No. 2310951 RF. A method of obtaining a hydrate of nickel oxide for an oxide-nickel electrode of an alkaline battery. 
IPC H01M 10/30, IPC H01M 4/26 / Volynskaya V.V., Volynsky V.V., Lopashev A.V., Semenov N.E., Tyugaev V.N., Chipiga I.V.: applicant and patentee Open Joint Stock Company "Plant of Autonomous Power Sources" Date of filing of the application and the priority of the invention from March 30, 2006, published on November 20, 2007 (In Russ.)

[7]. Verbol S.V., Zapariy M.M., Kozlov V.V. et al. Neutralization of galvanic sludge with the release of metals // Ecology and Industry of Russia, 2000, April, p. 28-29. (In Russ.)

[8]. Lurie Yu.Yu. Analytical Chemistry Handbook. Moscow: Chemistry, 1971, 454 p. (In Russ.)

[9]. Lazareva E.N., Egorov V.V., Olshanskaya L.N. et al. Processing of metal- containing galvanic sludge into multifunctional reagents // Ecological-legal and economic aspects of technogenic safety of regions: materials of the $\mathrm{V}$ Intern. scientificpractical conference Kharkov 19 - 21 October 2011 Kharkov: KhNADU, 2011, p. 324-327. (In Russ.)

[10]. Lazareva E.N., Olshanskaya L.N., Egorov V.V. et al. The use of sludge from electroplating industries in the manufacture of consumer goods // Journal «Polzunovsky Bulletin», 2011.-№ 4 - 2, p. 203-206. (In Russ.)

[11]. TU 48-3-63-90. Nickel nitrous hydrate. - L.: Standardization and metrology. 1990,36 p. The document TU 48-3-63-90 was provided by the LLC Production Company Lantan and transferred on 02.10.2019. (In Russ.)

Olshanskaya L. N. - Dr. Sc. (Chem.), Professor, Department of Ecology and Technosphere Safety, Saratov State Technical University named after Y. Gagarin, (Polytechnic st. 77, Saratov, 410054 Russian Federation).

Lazareva E. N. - Cand. Sc. (Chem.), Assoc. Professor, Department of Natural and mathematical sciences, Saratov State Technical University named after Y. Gagarin (Polytechnic st. 77, Saratov, 410054 Russian Federation).

Yakovleva E. V. - Cand. Sc. (Chem.), Assoc. Professor, Department of Ecology and Technosphere Safety, Saratov State Technical University named after Y. Gagarin, (Polytechnic st. 77, Saratov, 410054 Russian Federation).

\section{Просьба ссылаться на эту статью следующим образом:}

Выделение из гальваношламов гидроксида никеля и применение для изготовления катода Ni-Cd аккумулятора / Л. Н. Ольшанская, Е. Н. Лазарева, Е. В. Яковлева // Промышленные процессы и технологии. 2021. № 2. С. $35-43$.

DOI: $10.37816 / 2713-0789-2021-1-2-35-43$

\section{Please cite this article as:}

Olshanskaya L. N., Lazareva E. N., Yakovleva E. V. Isolation of nickel hydroxide from galvano sludges and application for the manufacture of a Ni-Cd battery cathode. Industrial processes ang Technologies, 2021, no. 2, pp. $35-43$

DOI: $10.37816 / 2713-0789-2021-1-2-35-43$ 